\title{
PEACE RESEARCH
}

Studies in arms control, disarmament, tension reduction, and similar fields of international relations frequently involve several scientific disciplines. Both physical and social scientists are involved in the applied science of what has come to be called "peace research".

To provide such research workers with a central source of reference data, the Canadian Peace Research Institute has established C.P.R.I. Abstracts. The Institute, directed by a 15-member board of scientists, academic and business leaders and financed by subscriptions from more than 25,000 Canadians, established C.P.R.I. Abstracts centre as one of the first three projects undertaken in 1962.

Directed by Drs. Alan and Hanna Newcombe who joined the Institute scientific staff last summer, the C.P.R.I. Abstracts now include more than 5,000 references to scientific material in such disciplines as psychology, sociology, economics, political science, law, as well as material from physical sciences, technical and engineering sources. More than 4,000 of these initial references have been prepared in abstract form on a card system. The abstract cards are coded for immediate selection of relevant material on any specific subject or classification of it. C.P.R.I. will now provide at a nominal charge either literature searches to indicate relevant material, or copies of the pertinent abstracts on reference cards.

To date English-language literature has been examined. Preparations are underway to engage abstractors who can prepare abstracts from foreign language publications, as well. However, abstracts in French, German, Scandinavian, Spanish, Italian, and Russian languages can be translated, if necessary, by C.P.R.I. personnel. About 30 abstractors are presently engaged under the Drs. Newcombes' direction. But more experienced abstractors with a background in a scientific discipline related to peace research fields are required.

The C.P.R.I. Abstracts cover Weapons, Technology and Strategy, Arms Control and Disarmament, Conflict and Tension, Ideologies, International Institutions including U.N. agencies, Regional and Military Alliances, National Policies, Crisis Areas, International Law, International Economics, Diplomacy, Decision-Making and Policy Formation, Methods of Study, Interactions of Science and Society. Each of these 15 subjects is divided into up to 100 sub-sections for ready reference.

Enquiries with regard to obtaining abstracts or literature searches or offering abstractor services should be directed to Dr. Hanna Newcombe, C.P.R.I. Abstracts, 25 Dundana Ave., Dundas, Ontario, Canada. 